\title{
(Re)escrituras del futuro: Historia de Mayta, de Mario Vargas Llosa ${ }^{1}$
}

\section{(Re)writings of the future: Mario Vargas Llosa's The Real Life of Alejandro Mayta}

\author{
Richard Leonardo \\ Universidad Nacional Mayor de San Marcos \\ Universidad San Ignacio de Loyola
}

\section{RESUMEN}

La crítica especializada ha considerado a Historia de Mayta (1984), novela de Mario Vargas Llosa, como un documento en el que su autor expresa sus fobias políticas e ideológicas hacia la izquierda peruana, llegando incluso a ridiculizarla; sin embargo, esta postura olvida que este texto es una novela y no un ensayo y, por lo tanto, el estatuto por el cual se rige es el ficcional. Esto no significa que esta novela evada la realidad, sino que se refiere a ella, pero de manera indirecta, apelando a un ejercicio metaficcional.

\section{Palabras clave:}

Vargas Llosa / Historia de Mayta / Metaficción / Apocalipsis / Contrautopía

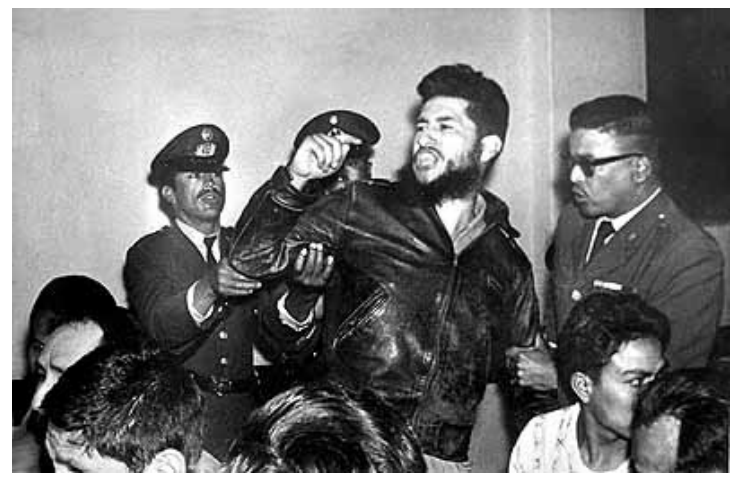

Hugo Blanco, dirigente trotskista, es arrestado por la policía cusqueña, tras haber impulsado tomas de tierras

\section{ABSTRACT}

The specialized criticism has considered Mario Vargas Llosa's The real life of Alejandro Mayta (1984) a document in which he expresses his political and ideological phobias about the Peruvian left, getting to the point of ridiculing it. However, said position leaves behind the fact that it is a novel and not an essay and, therefore, it is governed by fiction, which does not mean either that The real life of Alejandro Mayta pretends to escape from reality, it does refer to reality, but indirectly, by appealing to a metafictional exercise.

\section{Keywords:}

Vargas Llosa / The real life of Alejandro Mayta / Metafiction / Apocalypse / Against utopia

En efecto, las novelas mienten -no pueden hacer otra cosa-, pero ésa es sólo una parte de la historia. La otra es que, mintiendo, expresan una curiosa verdad, que sólo puede expresarse disimulada y encubierta, disfrazada de lo que no es.

Mario Vargas Llosa

1 Una primera versión de este trabajo apareció publicado con el título "Metaficción, apocalipsis y contrautopía en Historia de Mayta", en la revista Raído, núm. 14, pp. 11-22. 


\section{La literatura no refleja la vida}

En el prólogo que acompaña la edición del año 2005 de Historia de Mayta ${ }^{2}$, Mario Vargas Llosa escribe lo siguiente: "Sospecho que a pesar de su apariencia, esta novela no es solo la peor entendida y la más maltratada, sino la más literaria de todas la que he escrito, aunque sus apasionados críticos vieran en ella - oh manes de la ideología- solo una diatriba política" (p. 7). En este paratexto, como puede observarse, Vargas Llosa formula una queja en contra de aquella crítica que ha leído su novela privilegiando solamente los aspectos políticos e ideológicos de la misma. No es necesario ahondar mucho en los abordajes críticos que se han ocupado sobre esta obra para entender que el reclamo del escritor peruano tiene cierta validez. Con excepción de algunos autores (entre los que podríamos citar por ejemplo a Chrzanowski, 1986; Reisz, 1998, o Arbulú, 1990), el común denominador de los especialistas ha sido considerar esta novela como un texto político, cuya finalidad primordial sería la de desacreditar los diversos intentos de la izquierda peruana en contra del orden establecido ${ }^{3}$. Pese a que Historia de Mayta desarrolla un mundo diegético contrafáctico, estos estudiosos asumen que los enunciados que se presentan en esta novela de Vargas
Llosa son transferibles al mundo real efectivo. Me parece que aquellos críticos que defienden esta postura olvidan un aspecto básico de la teoría literaria: el estatuto de la realidad es distinto al estatuto de la literatura, lo que no significa, por supuesto, que estas dos instancias no guarden algún tipo de conexión ${ }^{4}$. Pensar de otro modo, implicaría caer en la trampa del "realismo ingenuo", es decir, creer que existe una correspondencia transparente entre los fenómenos externos y el texto literario, una correspondencia isomórfica entre aquello que sucede en el mundo factual y lo que se escribe acerca de este.

Historia de Mayta es una novela y, como tal, el mundo que representa en sus páginas no debe ser asumido como el mundo de la experiencia real. Se trata de una construcción verbal que si bien refiere hechos que se han suscitado en la realidad ${ }^{6}$, esto no significa que posea la capacidad de contarlos "tal como ocurrieron" efectivamente ${ }^{7}$. Para explicarlo en palabras harto conocidas: la literatura no "refleja" la realidad, sino que es una versión subjetiva de ella, una refiguración arbitraria y personal ${ }^{8}$. Pero, ¿qué es lo que impulsa a la mayor parte de los críticos que se ocupan sobre Historia de Mayta a sostener una opinión en contrario? Preguntemos mejor: ¿Por qué se cree que los contenidos y los juicios que vehicula este texto son "verdades" del mundo real y no parte de un mundo ficcional? Creo que esta situación es motivada por la peculiar arquitectura diegética que presenta esta novela de Vargas Llosa; un armazón en el que encontramos el desarrollo de una narración, pero, a la vez, un continuo acto de reflexión sobre esta última y el acto creador.

Historia de Mayta está estructurada en dos niveles narrativos: primero, a partir de una voz en primera persona, tenemos el nivel en el que un narrador-novelista nos relata sus esfuerzos por reconstruir la vida de Alejandro Mayta, para lo cual recaba una serie de informaciones mediante los testimonios de las personas que tuvieron algún tipo de relación con este personaje. Asimismo, encontramos un segundo nivel, desde una perspectiva omnisciente, en el que este narrador nos cuenta la vida de Mayta, desde que era un muchacho piadoso hasta que mucho tiempo después protagonizara, junto con el alférez Vallejos, una intentona política en la localidad de Jauja. Puede decirse que el primer nivel narrativo sirve como relato marco al segundo, que funciona como un relato enmarcado 0 - utilizando una categoría de la narratología modal- relato hipodiégetico ${ }^{9}$. La peculiaridad de este relato marco radica en que se constituye en un espacio discursivo en el que se reflexiona sobre la hipodiégesis, la que se va reformulando con el material que se extrae de este relato marco. En consideración a este rasgo estructural

2 La primera edición corresponde a 1984. En lo que sigue todas las citas que se realicen sobre la novela corresponden a la edición del 2005, citada en la bibliografía.

3 Cf. Cornejo Polar (1989, pp. 249-250); De Vivanco (2011 y 2013). Para algunos estudiosos, la homofobia de los camaradas de Mayta supone una crítica severa a la izquierda peruana, la que es representada como intolerante. Cf. Ingenschay (2011).

4 Como explica bien Garrido Domínguez, "Siempre hay lazos que conectan la realidad y los productos artísticos" (2011, p. 200).

5 Darío Villanueva (2004) denomina a esta tendencia "realismo genético".

6 Vargas Llosa detalla: "Esta novela nació gracias a un breve suelto que leí en Le Monde, a principio de los setenta, informando que una minirrebelión de un subteniente, un sindicalista y un puñado de escolares había estallado y sido aplastada casi al mismo tiempo en la sierra peruana" (2005, p. 9). Un texto revelador sobre el origen de esta novela es Génesis de la Historia de Mayta (1985) de Anne-Marie Mergier.

7 Como se sabe, la capacidad del lenguaje resulta siempre limitada, insuficiente y excedida por lo Real (Lacan) y, como consecuencia de ello, toda representación mediada por el lenguaje está condenada a ser igualmente limitada, insuficiente e incompleta. De lo que resulta, como dice Thomas G. Pavel, que un texto "solo puede ser una descripción infinitesimalmente parcial de su universo - aún a llegar a un nivel minúsculo requiere un proceso complejo" (1995, p. 83). Esperar que un texto "contenga" el íntegro de la realidad es una utopía. De otra parte, intentar amoblarlo tal como el mundo real significaría una tarea harto complicada. Lubomír Doležel explica: "Construir un mundo ficcional completo requeriría un texto de longitud infinita" (1999, p. 241).

8 Cornejo Polar opina en contrario: "En ese orden de cosas, aunque estuviera construida sobre la invención más libre la Historia de Mayta no se agota en el universo de la ficción: representa una forma de conciencia real sobre situaciones también perfectamente reales" (1989, p. 243)

9 Un segundo relato engendrado a partir de un primer relato que le sirve de base. Cf.: Reis, 1996, pp. $176-177$. 
es que Historia de Mayta puede ser catalogada como una metanovela ${ }^{10}$, es decir, "aquella novela que ante todo se refiere a sí misma como proceso de escritura, de lectura, de discurso oral, o como aplicación de una teoría exhibida en el propio texto" (Alter y Waug, citados en Quezada Gómez, 2009, p. 48) $)^{11}$. Esto es precisamente lo que sucede en el texto de Vargas Llosa que nos ocupa. Durante su lectura asistimos al despliegue de un mundo ficcional, pero, a la vez, la propia novela, en otro nivel narrativo, está reflexionando sobre sí misma, en una especie de relato especular. Es así que la novela se convierte en un curioso artefacto discursivo que performa aquello que teoriza a lo largo del recorrido narrativo. Pero la singularidad de Historia de Mayta no se agota aquí. Otro aspecto interesante de esta novela es que el relato marco "juega" a instaurarse como la "realidad misma", dejando para el relato enmarcado o hipodiegético la condición de mundo fictivo. En otras palabras: la novela propone que la realidad desde donde enuncia el narrador-novelista corresponde a la vida misma, al mundo real y concreto, y la hipodiégesis presentada tan solo es un producto de la imaginación propio del ámbito de la literatura. Cabe destacar que para lograr este cometido, el narrador-novelista se esfuerza por crear un lazo entre su mundo y el mundo de lo fáctico, en el que habita el autor, Mario Vargas Llosa, y nosotros, los lectores reales de la novela. Para este efecto, como anota bien Cornejo Polar, este narrador-novelista "desliza informaciones concretas y verificables: su trabajo en París, su actual residencia en Barranco, sus hábitos deportivos y - por supuesto- su condición de escritor" (1989, p. 250).

Tomando en cuenta la reflexión anterior, ¿puede afirmarse que la intención autorial que se desprende de esta novela es proponer como "verdad" de lo acontecido por Mayta y su fracasada revolución aquello que es narrado en el relato marco? En otros términos, ¿podemos dar por sentado que aquello que ocurrió en la vida real es lo que se nos está contando en este nivel de la narración? Si esto fuera así estaríamos frente a un relato de corte realista; es decir, tal como enseña Darío Villanueva (1994), uno en el que puede reconocerse la decidida pretensión de ocultar su condición literaria, su ficcionalidad misma, presentándose como la realidad efectiva y en la que no existiría manipulación ni mediación alguna de parte de un autor. Sospecho que nada más alejado de lo que nos presenta Historia de Mayta.

Si bien es cierto que en esta novela se percibe una vocación por suplantar la realidad (al proponer diversas estrategias retóricas que apuntan a crear un espacio indiscernible entre esta realidad y la ficción); también lo es que, en el propio recorrido narrativo, presenciamos un desmantelamiento brutal de la "ilusión de realidad" (Barthes) que impone el propio texto. La novela establece que estamos precisamente ante una novela, un fruto de la ficción. Este hecho se observa en el capítulo final de esta obra de Vargas Llosa. El narrador-novelista ha decidido ir a buscar a Mayta para confrontarlo y llegar así al fondo del asunto que está investigando: la razón por la que fracasó la intentona política de Jauja. En ese trance decide contarle a Mayta sobre el libro que está escribiendo:

- Me he pasado un año investigando sobre usted, conversando con la gente que lo conoció - le digoFantaseando y hasta soñando con usted. Porque hezue, aunque de manera muy remota, tiene que ver con la historia esa de Jauja.

Me mira sin decir nada, ahora sí sorprendido, sin comprender, sin estar seguro de haber oído bien, ahora sí inquieto.
-Pero... - tartamudea-. Por qué se le ocurrió, cómo ha sido eso de...

-No sé por qué ni cómo, pero es lo que he estado haciendo todo este año - le digo, con precipitación, atemorizado de su temor, de que se niegue a seguir esta charla, a tener otra. Le aclaro-: En una novela siempre hay más mentiras que verdades, una novela no es una historia fiel. Esa investigación, esas entrevistas, no eran para contar lo que pasó realmente en Jauja, sino, más bien, para mentir sabiendo sobre qué mentía. (p. 339)

Como se aprecia, el narrador-novelista le ha confesado a Mayta que está escribiendo una novela sobre la revuelta que este protagonizó en la sierra central. Precisamente, la novela que estamos leyendo en el nivel de la hipodiégesis. Con esta decisión narrativa, el relato marco ha socavado los cimientos mismos sobre los que se estaba construyendo el relato enmarcado (la puesta en escena de la intentona política). Esta hipodiégesis no es más aquello que efectivamente ocurrió en la realidad, sino que resulta siendo, apenas, una elucubración literaria, un artificio ficcional de este narrador-novelista. Para que no le quede duda a Mayta (ni a nosotros, los lectores reales de la novela), este narrador-novelista le enfatiza el aspecto fictivo de su creación al diferenciarla del mundo real:

—Por supuesto que no aparece su
nombre verdadero-le aseguro-.
Por supuesto que he cambiado
fechas, lugares, personajes, que
he enredado, añadido y quitado
mil cosas. Además, inventé un
Perú de apocalipsis, devastado
por la guerra, el terrorismo y las
intervenciones extranjeras. Por
supuesto que nadie reconocerá

-Por supuesto que no aparece su nombre verdadero - le aseguroPor supuesto que he cambiado fechas, lugares, personajes, que he enredado, añadido y quitado mil cosas. Además, inventé un Perú de apocalipsis, devastado por la guerra, el terrorismo y las supuesto que nadie reconocerá

10 Comparte esta idea Dieter Ingenschay (2011, p. 55).

11 José María Merino amplía este concepto: "A menudo se utilizan los términos metaliteratura, metanovela, metaficción, para denominar ciertas formas narrativas que sobrepasan lo que aparentemente debieran ser sus límites naturales —el espacio convencional del relato, como ámbito subsidiario de la realidad, como simulacro que tiene sus propias reglas, al margen de lo verdadero o lo falso de dicha realidad-, con la pretensión de competir con ella, de convertirse en realidad, más allá del simulacro." (2005, p. 82. Cursiva en el original). 
nada y que todos creerán que es pura fantasía. He inventado también que fuimos compañeros de colegio, de la misma edad y amigos de toda la vida. (p. 340)

Los dos párrafos de la novela anteriormente citados son sumamente interesantes, porque evidencian una serie de aspectos sobre la poética que desarrolla este narrador-novelista en la construcción y puesta en escena de su novela. De sus palabras se desprende, por ejemplo, que reconoce la autonomía del texto literario respecto a la realidad $y$, además, asume que la literatura no tiene como finalidad última ser un documento fidedigno 0 testimonial de lo real. En una novela, le explica a Mayta, "siempre hay más mentiras que verdades"; no se trata de "una historia fiel". Con esto pareciera decirnos este narrador-novelista que no estamos ante la realidad, sino ante un simulacro de la misma. Y, a la par, que una novela no se encarga de "contar" verdades, sino mentiras (ficciones). En este sentido, es significativo que este narrador-novelista le recalque a Mayta que toda su labor investigativa no apunte a "restaurar" lo que realmente ocurrió en Jauja; su objetivo es suministrarse de los elementos de juicio necesarios que le posibiliten elaborar una construcción ficcional que sea lo suficientemente verosímil. 0 sea, una ficción que no se aparte del referente, más bien que tenga el poder de evocarlo indicial 0 icónicamente. De otro lado, en este diálogo entre el narrador-novelista y Mayta, el primero explicita en qué consiste su labor creadora. No se propone copiar la realidad, no busca "reflejarla"; tan solo la cambia, la reajusta, la tergiversa en función a su parecer. Todo esto en una "mentira mayor": un Perú apocalíptico, devastado por la guerra, el terrorismo y las intervenciones extranjeras.
Con esta confesión de parte, como ya se dijo, el narrador-novelista ha ejecutado un acto suicida: ha minado la verosimilitud de la historia que nos estaba narrando. Todo aquello que nosotros los lectores suponíamos cierto no es más que una vulgar mentira, una ensoñación producto de la imaginación de este creador literario. He aquí un elemento más que ratifica a Historia de Mayta como metaliteratura, porque, como explica Catalina Quezada Gómez:

En una de sus múltiples vertientes, la metaliteratura se subleva contra esa impostura [se refiere al realismo], con recursos desenmascaradores, dejando al descubierto las estructuras narrativas y llamando la atención del lector sobre la ficcionalidad textual, haciéndole ver que lo que lee es literatura. (2009, p. 56).

Me parece que es pertinente preguntarse, ahora, ¿por qué esta necesidad del narrador por boicotearse a sí mismo y al trabajo realizado a lo largo de la novela? ¿Qué lo motiva a desmantelar el mundo que ha erigido tan laboriosamente? Tengo la impresión de que este acto no es gratuito, sino que se debe principalmente a la puesta en escena de aquello que el narrador-novelista no se ha cansado de predicar en el texto: la literatura no es la vida. Y como tal, el conocimiento que podemos extraer de ella no es fidedigno, verídico 0 testimonial ${ }^{12}$, se trata más bien de un saber subjetivo y, por ende, relativo y arbitrario. Con esta decisión narrativa no solo se está cuestionando la versión de los hechos que el narrador-novelista elabora acerca de la revuelta protagonizada por Alejandro Mayta, sino que se pone en evidencia la pretensión del realismo como artefacto capaz de aprehender y reproducir la realidad y, a la par, del mismo lenguaje como instrumento imposibilitado de recuperar lo real ${ }^{13}$. No obstante, hay que dejar en claro que esta condición que se le asigna a la literatura en el texto de Vargas Llosa, no implica que el narrador-novelista considere que su texto no pueda ayudarnos a entender la realidad a la que alude. Por el contrario, Historia de Mayta pareciera enunciar como verdad que el saber que nos proporciona obedece a otro orden de cosas, uno en el que lo cognitivo pasa por lo emocional o sentimental ${ }^{14}$. Para ilustrar este punto, citemos parte de la conversación entre la madre de Mayta y el narrador-novelista:

Doña Josefa Arrisueño me mira y yo sé lo que piensa. Quisiera tranquilizarla, disipar sus dudas, pero es imposible porque, a estas alturas, sé tan poco de mis proyectos sobre Mayta como ella misma.

- ¿Y qué va a escribir sobre él? — murmura, pasándose la lengua por los labios carnosos- ¿Su vida?

—No, su vida no — - re respondo, buscando una fórmula que no la confunda más-. Algo inspirado en su vida, más bien. No una biografía sino una novela. Una historia muy libre, sobre la época, el medio de Mayta y las cosas que pasaron en esos años. (p. 25)

En este diálogo se evidencia el propósito del narrador-novelista por contar la historia de Mayta: no se trata sencillamente de recrear la vida de este personaje (no le interesa escribir una biografía), sino que el evocarla literariamente le permitirá acceder a una serie de cuestiones relacionadas a ella, como "la época", "el medio", "las cosas que pasaron en esos años". En otras palabras: Mayta es un pretexto para hablar del pasado, de la sociedad de aquel entonces y de los problemas que aquejaron a los individuos que formaron parte de ella.

12 Birger Angvik considera que "Historia de Mayta parodia, para degenerarlo, el género narrativo hispanoamericano de la novela testimonial" (2004, p. 233). Me parece que la propuesta de Vargas Llosa no necesariamente se limita a esta situación. Pienso que el cuestionamiento es mayor y se refiere al carácter de la literatura como instrumento mimético.

13 En este sentido, Historia de Mayta puede ser catalogada como una metaficción histórica. Amalia Pulgarín nos explica, en base a los planteamientos teóricos de Linda Hutcheon, que en este tipo de textos los autores "son conscientes de que tanto la narración histórica como la narración ficticia son construcciones o productos humanos y esta problemática la transportan a sus textos" (1995, p. 14).

14 Inevitable no pensar en la noción de literatura que propone Pierre Macherey (1978), quien considera a esta como un mapa sentimental, emotivo de la sociedad. 
Ahora bien, ¿a qué obedece este ejercicio de exhumación histórica? ¿Por qué el narrador-novelista debe recomponer aquello que ocurrió en Jauja? Porque, a su entender, el caos que experimenta su sociedad tiene como punto de inflexión la revuelta de los años cincuenta que protagonizó Mayta en los Andes. Hay en ese acontecimiento histórico la explicación de los eventos políticos y sociales que se experimentan en el presente de este narrador-novelista. Por eso, la necesidad urgente de escudriñar en ese pasado "del que nadie quiere hablar" $\mathrm{y}$, al parecer -a juicio de este narrador-novelista-, es el causante del desorden generalizado del presente que se enuncia en el relato marco. Es así que en el texto se manifiesta explícitamente tal motivación. El narrador, al ser nuevamente inquirido por la razón que lo lleva a escribir sobre Mayta, reflexiona del siguiente modo: "—No sé, hay algo en su caso que me atrae más que el de otros [revolucionarios]. Cierto simbolismo de lo que vino después, un anuncio de algo que nadie pudo sospechar entonces que vendría" (Vargas Llosa, 2005, p. 60). Y líneas más abajo leemos:

Tal vez tiene razón [se refiere a unos de sus entrevistados], tal vez sea por el carácter precursor de aquella aventura. Es verdad, ella inauguró una época en el Perú, algo que ni Mayta ni Vallejos pudieron adivinar en ese momento. (p. 61)

Insistamos una vez más: el narrador -novelista asume como verdad que el escribir sobre Mayta, sobre su intentona revolucionaria del pasado, le permitirá reflexionar sobre el estado de cosas actual por la que atraviesa su sociedad $^{15}$, que se representa como la diégesis en el relato marco. Esta realidad es la de un Perú sumido en un desorden total por culpa de la violencia política, una nación que se debate en el apocalipsis mismo. Ahora bien, ¿por qué apelar a la figura del apocalipsis para referirse a la realidad desde la que enuncia el narrador-novelista?, ¿por qué representar un Perú arrasado por la corrupción extrema y la podredumbre? Antes de dar respuesta a estas interrogantes, creo que es importante detenernos a analizar la manera en la que está configurada esta representación de un Perú apocalíptico.

\section{(Re)escrituras del futuro: contrautopía y apocalipsis}

Uno de los aspectos más interesantes de Historia de Mayta es que el relato marco, en el que se producen las conversaciones sobre el levantamiento fallido del personaje principal, nos presenta una especie de contrautopía 0 antiutopía. Entiendo esta noción, básicamente, como opuesta a la utopía. El Diccionario de la Real Academia de la Lengua Española define esta última en los siguientes términos: "1. f. Plan, proyecto, doctrina deseables que parecen de muy difícil realización.”, y “2. f. Representación imaginativa de una sociedad futura de características favorecedoras del bien humano" (DRAE, 2014). En efecto, en Historia de Mayta, en el relato marco, la representación de la sociedad peruana está signada por el horror y el caos generalizado. No presenciamos una situación deseable, sino, todo lo contrario, asistimos a la debacle de la sociedad peruana. Esto debido al avance de las huestes revolucionarias marxistas que han logrado "capturar" al país entero y lo han doblegado políticamente, con ayuda de fuerzas comunistas extranjeras. En el texto, el profesor Ubilluz, personaje que traiciona a Mayta, le dice al narrador-novelista: "Un Juez me contaba el otro día, que, según un coronel de Estado Mayor, la estadística secreta de las Fuerzas Armadas ha registrado ya medio millón de muertos desde que esto comenzó" (p. 164).

El presente de la novela es errático y sangriento. Los insurrectos han hecho suyas muchas ciudades del Perú. Lima está a punto de ser sitiada (ya ni siquiera sus lugares social y económicamente exclusivos, como Miraflores, están exentos de la violencia). El Estado, dirigido por una Junta Militar, ha sido incapaz de detener la ola subversiva y, ahora, el Perú corre el riesgo de ser invadido por los comunistas del resto de Latinoamérica. El narrador -novelista expresa dubitativo:

Estamos en el convaleciente Café Haití de Miraflores, que no acaba de reparar los destrozos del atentado: sus ventanas aún carecen de cristales y el mostrador y el suelo siguen rotos y tiznados. Pero aquí, en la calle, no se nota. A nuestro alrededor todo el mundo habla de lo mismo, como si los parroquianos de la veintena de mesitas participaran de una sola conversación: ¿será cierto que tropas cubanas han cruzado la frontera con Bolivia? ¿Que, desde hace tres días, los rebeldes y los "voluntarios" cubanos y bolivianos que los apoyan hacen retroceder al Ejército y que la Junta ha advertido a Estados Unidos que si no interviene los insurrectos tomarán Arequipa en cuestión de días y podrán proclamar allá la República Socialista del Perú? (p. 178).

El país entero está postrado ante la "insania revolucionaria". Al poco tiempo, la amenaza de la invasión internacional se cumple y la única solución posible es la llegada de los "marines" norteamericanos, afincados en el Ecuador. Mientras tanto, el sufrimiento y el horror adquieren el valor de moneda común en nuestro territorio. Para ilustrar este punto baste citar lo que en el relato marco se narra sobre el asalto a la ciudad del Cusco por parte de los revolucionarios y su posterior bombardeo a cargo de las fuerzas del gobierno: 
Como hay tantos muertos y no es posible enterrarlos, los comandantes rebeldes ordenan rociarlos de cualquier materia inflamable y prenderles fuego. Hay que evitar que los restos putrefactos desperdigados por la ciudad propaguen infecciones. El aire es tan espeso y viciado que apenas se puede respirar [...]. La crepitación de las hogueras donde arden los cadáveres no acalla las voces irascibles, enloquecidas, de los parientes y amigos que tratan de impedir la quemazón, exigiendo sepultura cristiana para las víctimas. En medio del humo, la pestilencia, el pavor y la desolación, algunos tratan de arrebatar los cadáveres a los revolucionarios. De una cofradía, iglesia o convento sale una procesión. Avanza, fantasmal, salmodiando rezos y jaculatorias, entre la mortandad y la ruina que es el Cusco. (p. 229)

El dolor, parafraseando un verso del poeta César Vallejo, está por todas partes. La ciudad de Cusco entera llora por sus muertos insepultos. Resalta impactante la imagen de los revolucionarios quemando los cuerpos de la gente del pueblo, ya no se trata de cuerpos que deban ser ideologizados, sino que son cuerpos peligrosos porque trasmiten enfermedad y muerte, y por eso deben ser incinerados.

A poco de transcurrir esta escena, las fuerzas del orden bombardean otra vez la ciudad, intentando acabar con los insurrectos. No les interesa si en el ataque se producen bajas civiles que no tienen nada que ver en el conflicto. Sin embargo, los revolucionarios logran huir, pero el espectáculo que han dejado detrás de ellos es goyesco:

¿Y esos puntitos negros, volanderos, innumerables, que acudían de los cuatro puntos cardinales hacia el
Cusco? No eran cenizas sino aves carniceras, voraces, hambrientas, que, aguijoneadas por el hambre, desafiando el humo y las llamas, caían en picada hacia las presas codiciables. Desde las alturas, los sobrevivientes, los parientes, los heridos, los combatientes, los internacionalistas, podían, con un mínimo de fantasía, escuchar la trituración afanosa, el picoteo enfebrecido, el aletear abyecto, y sentir el espantoso hedor. (p. 239)

Ahora, la pregunta que emerge es ¿quién 0 qué es el responsable de esta matanza? La verdad del texto enuncia que son los revolucionarios comunistas. Pero precisemos más: es la ideología marxista. Con sus acciones, y respaldado por estas ideas subversivas, estos revolucionarios no solo han precipitado que la democracia fracase al rendirse ante una Junta Militar, sino que han puesto en riesgo la patria, que fue invadida tanto por los comunistas internacionales como por los "marines" norteamericanos. De otro lado, nótese que los más perjudicados en esta aventura son las personas que pertenecen al pueblo, quienes al final quedan expuestos al dolor y el sufrimiento. Como puede apreciarse estamos ante una contrautopía 0 antiutopía. El relato marco representa una realidad excepcional en la que no hay nada de esperanzador y, lo más curioso, es que esto que se narra asume la categoría de lo posible.

Al inicio de nuestro artículo postulamos que en Historia de Mayta podíamos diferenciar dos niveles diegéticos: el relato marco, en el que se desarrollan las conversaciones sobre el conato revolucionario de Mayta, y el relato enmarcado, hipodiégetico: que consigna lo evocado por las conversaciones de los entrevistados por el narrador-novelista. Sin embargo, en el capítulo final este último le revela a Mayta (y a nosotros junto con él) que mucho de aquello que se narró es fal- so, apenas una mentira. Por ejemplo, es "mentira" que el Perú experimente una situación de apocalipsis, que esté devastado por la guerra, el terrorismo y las intervenciones extranjeras. Por supuesto que también es un "engaño" el asedio de Lima y el bombardeo del Cusco. Pero, ¿por qué el narrador -novelista construye una hipodiégesis de esta naturaleza? ${ }^{16}$. Y, además, ¿cuál es la función que cumple este artificio en el proyecto discursivo que vehicula la novela? Pienso que este relato enmarcado pretende funcionar como una predicción de lo que podría pasar en una situación similar, en la que los comunistas intenten tomar el poder por la fuerza sin considerar las consecuencias que podrían acarrear para el resto de los peruanos ${ }^{17}$. He aquí la importancia de este virtuosismo técnico. A partir de esto el narrador logra tender una línea de sentido que conecta esta hipodiégesis con la realidad que se desarrolla en el relato marco y, a su vez, en un movimiento magistral, con la realidad fáctica en la que se mueve el lector real, el verdadero destinatario del mensaje que la obra transmite.

El relato apocalíptico funciona como una lección en negativo sobre aquello que no se debe permitir de ningún modo: la emergencia y el posicionamiento de fuerzas políticas que no comparten el sistema democrático. Si no se le hace caso a esta lección lo que postula el texto es que el Perú real podría terminar como el Perú de esta hipodiégesis contrautópica 0 antiutópica. De esta manera, Historia de Mayta se constituye no solo como una reescritura del pasado, sino que se convierte en invención, búsqueda y profecía - una profecía que intenta manipular al lector mediante la presentación de una realidad probable. Ahora, ya entendemos el por qué del ejercicio realizado por el narrador en descalificar a los revolucionarios y a su ideología. Por más que se presente como un escritor realista y, como tal, neutral y desprejuiciado, lo cierto es que asume

16 Carlos Schwalb la denomina "una mitología del caos nacional" (2005, p. 96).

17 De Vivanco opina que "el mito apocalíptico no sirve únicamente para darle significado a la novela sino principalmente al Perú que inspira la ficción. No se trata de una ficción que recrea un hecho histórico sino más bien de un país que muestra una 'esencia' ficcional en el sentido más peyorativo que se le puede dar a este concepto: mentira, irracionalidad, ingenuidad, infantilismo" (2011, p. 15). 
un papel judicatorio, de condena. Desde una posición ideológica determinada (que aunque no se encuentra explícita en el texto puede fácilmente inferirse luego de la lectura de la novela), nos despliega una realidad aleccionadora que sirve como ejemplo de aquello que podría ocurrir en la realidad. Esta es la razón por la cual, a lo largo del recorrido narrativo, este narrador -novelista se esfuerza por exacerbar los referentes del mundo real efectivo (nombres de personas, ciudades, calles, establecimientos públicos). De esta manera, se busca que el impacto sobre el lector sea mayor y contundente, como en una película en la que los espectadores pueden reconocer su realidad y reconocerse en la misma, una película que avizora un trágico final.

\section{CODA}

Debe recordarse que la época en la que se publica Historia de Mayta, los primeros años del periodo de la violencia política en el Perú, todavía no se aquilataba cabalmente el horror de esta guerra interna. En este sentido, me parece que este texto de Vargas Llosa puede leerse como una lección a futuro de lo que podría esperarle al país si dejara germinar estas ideas y acciones revolucionarias. Es así que nos encontramos ante una advertencia de lo que podría significar el dogmatismo y sus consecuencias para la nación peruana. Para llevar a cabo esta intención autorial, Vargas Llosa apela a un mecanismo metaficcional, cual es presentar una historia en la que se reflexiona sobre otra historia con la que establece una serie de relaciones efecto-causales. Para agudizar aún más esta impresión recurre, a su vez, a la creación de una realidad monstruosa, apocalíptica, en la que el Perú se debate en un caos generalizado por culpa de la ideología marxista. De esta manera, el autor de Historia de Mayta no solo está proponiendo una profecía de aquello que podría pasar en una eventualidad histórica determinada —el triunfo de estas ideas de izquierda-, sino de un juicio severo y descalificador de esta tendencia política e ideológica. Para Vargas Llosa no hay duda posible: el marxismo solo le puede traer el horror y el caos a la nación peruana (curiosa posición respecto de una ideología por la que durante mucho tiempo experimentó algún tipo de afecto intenso).

\section{Bibliografía}

Angvik, B. (2004). Historia de Mayta: novelas de parodias y sátira. En B. Angvik, La narración como exorcismo (pp. 213-204). Mario Vargas Llosa. Obras (1963-2003). Lima: Fondo de Cultura Económica.

Arbulú, I. S. (1990). Historia de Mayta: ¿una novela metaficcional? [Tesis para optar el grado de bachiller]. Pontificia Universidad Católica del Perú.

Chrzanowski, J. (1986). Historia de Mayta de Mario Vargas Llosa. Anales de la literatura hispanoamericana, (15), 211-218.

Cornejo Polar, A. (1989). La historia como apocalipsis (sobre Historia de Mayta de Vargas Llosa). En A. Cornejo Polar, La novela peruana (pp. 243-256). Lima: Horizonte.

De Vivanco, L. (2011). El capítulo PCP-SL en la narrativa de Mario Vargas Llosa. Revista Chilena de Literatura, (80), 5-28.

De Vivanco, L. (2013). Historias del más acá. Imaginario apocalíptico en la literatura peruana. Lima: Instituto de Estudios Peruanos.

DoležEL, L. (1999). Heterocósmica. La ficción y mundos posibles. Madrid: Arco/Libros.

GarRido Domínguez, A. (2011). Narración y ficción. Literatura e invención de mundos. Madrid-Frankfurt: Iberoamericana -Vervuert.

IngensChay, D. (2011). Mario Vargas Llosa y el "pecado nefando". Revista Chilena de Literatura, (80), 51-63.

Leonardo, R. (2013). Metaficción, apocalipsis y contrautopía en Historia de Mayta. Raído, (14), 11-22.

Macherey, P. (1978). A Theory of Literary Production. Londres: Routledge y Kegan Paul.

Mergier, A. M. (1985). Génesis de la Historia de Mayta. Huellas, (14), 10-14. 
Merino, J. M. (2005). Los límites de la ficción. Anthropos, (208), 82-91.

Pavel, G. H. (1995). Mundos de ficción. Caracas: Monte Ávila Latinoamericana.

Pulgarín, A. (1995). Metaficción historiográfica. La novela histórica en la narrativa hispánica posmodernista. Madrid: Fundamentos.

Quezada Maldonado, C. (2009). La metanovela hispanoamericana en el último tercio del siglo xx. Madrid: Arco/Libros.

Real Academia Española y Asociación de Academias de la Lengua Española (2014). Diccionario de la lengua española. Madrid: Espasa Calpe.

ReIs, C., y Lopes, A. C. (1996). Diccionario de narratología. Salamanca: El Colegio de Salamanca.

Reisz de Rivarola, S. (1986). La historia como ficción y la ficción como historia. Vargas Llosa y Mayta. Hueso Húmero, (21), $112-134$.

SchwalB, C. (2001). Mario Vargas Losa: Historia de Mayta y las mentiras de la historia. En C. Schwalb, La narrativa totalizadora de José María Arguedas, Julio Ramón Ribeyro y Mario Vargas Llosa (pp. 75-106). Nueva York: Peter Lang.

Vargas Llosa, M. (2005 [1984]). Historia de Mayta. Barcelona: Alfaguara.

Villanueva, D. (1994). Fenomenología y pragmática del realismo literario. En Avances en teoría de la literatura (pp. 165-185). Santiago de Compostela: Universidad de Santiago de Compostela.

Villanueva, D. (2004). Teorías del realismo literario. Madrid: Biblioteca Nueva. 